\title{
Visokošolski zavodi in tržna dejavnost: primer Slovenije in tujine
}

UDK: 378:339.138(045)

\author{
Mojca Potočnik Kogovšek \\ Univerza v Ljubljani, Fakulteta za arhitekturo \\ mojca.kogovsek@fa.uni-lj.si
}

\section{IZVLEČEK}

V članku so podani številni argumenti, ki govorijo v prid uvajanju tržne dejavnosti na visokošolskih zavodih. Opisan je predlog potrebnih in mogočih organizacijskih preureditev, ki izvirajo iz potrebe po večji dinamičnosti in tržni konkurenčnosti visokošolskih zavodov. Dokazana je povezava med kakovostno organizirano tržno dejavnostjo na visokošolskih zavodih in možnostjo njihovega vsestranskega razvoja ter krepitve njihove konkurenčnosti, poudarjeni so pozitivni učinki povezovanja fakultet s prakso pri krepitvi vezi med akademskim in strokovnim okoljem, kar bo v prid vsem zaposlenim, stroki in študentom. Hkrati se potrjuje hipoteza, da je tržna dejavnost neizogibno potrebna, če želijo pedagogi ohraniti in razvijati stik z živo stroko, kar kažejo težnje pri razvoju evropskega visokega šolstva. To sta potrdili tudi anketa, izvedena na tujih fakultetah, in analiza sodobnih gibanj v razvoju evropskega visokega šolstva.

Ključne besede: izobraževanje, javna služba, tržna dejavnost,

JEL: 1.02 konkurenčnost, visokošolske ustanove.

\section{Uvod}

$\checkmark$ mnogih državah EU se pojavlja težnja, da bi postale izobraževalne ustanove javnega sektorja bolj povezane s prakso, cenovno dostopnejše najširšemu krogu mladine in bile hkrati bolj konkurenčne, zato si prizadevajo za uvajanje tržnih in navidezno tržnih elementov tudi $v$ javni sektor. Za dosego tega cilja uporabljajo različne mehanizme, kot so uvedba svobodnega trga, kar 
Mojca Potočnik Kogovšek

Visokošolski zavodi in tržna dejavnost:

primer Slovenije in tujine

je mogoče izpeljati z ukinitvijo posameznih monopolov v javnem sektorju (npr. na področju telekomunikacij) ali s privatizacijo združb in služb $\vee$ javnem sektorju. $\vee$ visokem šolstvu naj bi bila konkurenčnost trga rešitev za dosego boljših rezultatov na področju izobraževanja in bolj neodvisno financiranje ustanov. Zato sta se temi privatizacije in konkurenčnosti trga pojavili na dnevnih redih visokega šolstva v številnih državah. Izoblikovalo se je mnenje, da privatizacija spodbuja učinkovitost vseh udeleženih $v$ visokem šolstvu, pa naj bodo to študentje ali vodstva ustanov (Goedegebuure at al., 1993). Večja tekmovalnost med univerzami, ki je posledica tržnega pristopa in prehoda iz monopolnega, z državo zaščitenega položaja univerz, v kompetitivne marketinške razmere, terja prilagoditev tradicionalnih oblik univerzitetne organiziranosti novim razmeram (Neave, 2000).

Takšnemu procesu smo trenutno priča tudi v Sloveniji. Slovenske državne univerze in visokošolski zavodi sodijo med javne zavode, ki so imeli še do nedavnega $v$ slovenskem prostoru na področju visokošolskega izobraževanja monopolni položaj. Z razvojem zasebnega šolstva, ki je osnovano na tržnih načelih in je tudi sicer kadrovsko in organizacijsko bolj gibčno, je bilo vzpostavljeno tudi $\checkmark$ Sloveniji novo konkurenčno okolje, ki se mu bodo morali dolgoročno prilagoditi tudi javni visokošolski zavodi, ki opravljajo javno službo $v$ javnem interesu in za javna sredstva. Zato opravljajo javni zavodi tržno dejavnost le izjemoma, saj je njihovo nastopanje na trgu lahko v koliziji z njihovim temeljnim poslanstvom. Kljub takšni načelni ugotovitvi pa so visokošolski zavodi kot javni zavodi v posebnem razmerju do prakse oziroma nastopanja na trgu. Ustvarjanje in posredovanje novega znanja namreč ni mogoče zgolj na podlagi razvijanja teoretskih znanj, temveč se lahko takšno znanje razvija, posreduje in izmenjuje le $\vee$ neposrednem stiku z živo prakso. Glede na povedano se zastavlja nekaj vprašanj oziroma problemov:

1) Ali podpirati tržno dejavnost v okviru slovenskih visokošolskih zavodov ali ne?

2) Ali naj se izvaja tržna dejavnost $v$ imenu fakultet ali v imenu univerz?

3) Kakšna naj bodo razmerja med opravljanjem javne in tržne dejavnosti visokošolskih zavodov?

Odgovore na gornja vprašanja sem izoblikovala $v$ specialistični nalogi z naslovom Visokošolski zavodi in tržna dejavnost, s katero sem želela dokazati povezavo med kakovostno organizirano tržno dejavnostjo visokošolskih zavodov in možnostjo njihovega vsestranskega razvoja in konkurenčnosti, predvsem pa opozoriti na pozitivno plat povezovanja fakultet s prakso pri 
vzpostavljanju vezi med akademskim in strokovnim okoljem, kar bo predvsem $\checkmark$ prid študentom.

\section{Opredelitev hipotez}

V zvezi z obravnavano tematiko se ponujajo tri izhodiščne hipoteze:

a) da je tržna usmerjenost visokega šolstva pomembna za spodbujanje večje tekmovalnosti med vsemi tipi visokošolskih ustanov. Večjo tekmovalnost spodbuja vse bolj negotovo in nestalno državno financiranje. Potreba po dodatnih neproračunskih sredstvih ustvarja tekmovalne razmere, ki silijo ustanove $\mathrm{k}$ reformam notranje organizacijske strukture, kar prispeva k večji učinkovitosti in hkrati k oblikovanju inovativnih akademskih, raziskovalnih ter spremljajočih programov, zanimivih za študente kot za uporabnike. S sredstvi iz tržne dejavnosti se deloma financira izvajanje temeljne dejavnosti.

b) da je prestrukturiranje notranje organizacijske strukture visokošolskih ustanov nujno za prilagoditev javnih zavodov novim družbenim in ekonomskim razmeram na trgu znanja. Uvajanje tržne dejavnosti po načelih bolonjske deklaracije zahteva od visokošolskih ustanov ponudbo novih tržno zanimivih programov, kar vodi v proces diferenciacije kot oblike pospešenega drobljenja ustanov $v$ nove specializirane enote. Večja razdrobljenost zahteva ponovno integracijo oziroma nove oblike povezovanja ter prestrukturiranje notranje organizacijske strukture visokošolskih ustanov. Ohraniti je treba klasično hierarhično obliko komunikacije med akademskimi skupinami, administracijo in vodstvom ter hkrati omogočiti potrebno horizontalno povezovanje med akademskimi skupinami, kar spodbuja njihovo večjo prilagodljivost na trgu in akademsko inovativnost.

c) da je povezovanje visokega šolstva z gospodarstvom pomembno za strokovni, znanstveni, pedagoški in ekonomski razvoj visokošolskih zavodov. Izvaja se v okviru fakultet, kar omogoča njihovo optimalno konkurenčnost in fleksibilnost na trgu, hkrati pa to zagotavlja fakultetam potrebno strokovno promocijo. Tržno dejavnost izvajajo visokošolski zavodi $v$ interesu vseh zaposlenih, študentov in uporabnikov. 
Mojca Potočnik Kogovšek

Visokošolski zavodi in tržna dejavnost:

primer Slovenije in tujine

\section{Novi modeli organiziranosti visokega šolstva}

$\checkmark$ večini evropskih držav težijo k organiziranosti visokega šolstva, ki temelji na tradicionalnih oblikah, a hkrati uvajajo nove metode, ki jih zahteva sodobno organizirana družba. Primerjave iščejo $\vee$ organizacijskih modelih sodobnih gospodarskih organizacij, ki so bolj dinamično organizirane kot tradicionalni visokošolski modeli (Kogan 1992, str. 63-68). Že po tradiciji so bile visokošolske institucije drugačne tako po svoji notranji organizaciji kot po načinu dela. Učitelji imajo veliko svobodo ustvarjanja in več načinov interpretacije svojega znanja, kar ima za posledico ohlapnejšo organiziranost univerz z manj izraženo hierarhijo $v$ administriranju in manjšo vlogo vodstvenega kadra, ki ima pri svojem delu omejene pravice odločanja. Dejavnost visokošolskih institucij (raziskovanje, ohranjanje in razširjanje znanja) je $v$ nasprotju z gospodarskimi organizacijami pretežno neprofitna. Cilji univerz so veliko dolgoročnejši, kot je to mogoče pričakovati $v$ gospodarskih organizacijah. Ni nekega enotnega najboljšega načina organizacije. Izbor je odvisen od številnih dejavnikov, ki jih pogojuje spremenjeno sistemsko okolje visokošolskih organizacij. Univerze in fakultete lahko razumejo spremembe kot novo priložnost in izziv za notranjo preobrazbo. Lahko se osvobodijo vpliva države in se povežejo z gospodarstvom ali raziskovalnimi institucijami, se odprejo trgu, povečajo število izrednih študentov in podobno. Postati morajo "odprti sistemi", ki se nenehno odzivajo na spremembe v okolju. Negotovost na področju državnega financiranja naj bi spodbujala prilagajanje novim družbeno - ekonomskim razmeram (Neave, 2000).

Za organizacijsko ureditev ustanov visokega šolstva sta bistvena dva temeljna procesa, namreč proces diferenciacije in proces integracije. Trg narekuje potrebo po novih specializiranih visokošolskih programih, po novih pedagoških in raziskovalnih enotah. Diferenciacija je zato nujna, vendar vodi $k$ drobljenju organizacij. Zato je treba sočasno razvijati komplementaren proces integracije, ki spodbuja sodelovanje med različnimi enotami (Clark in Burton, 1995, str. 159-169). 
Mojca Potočnik Kogovšek

Visokošolski zavodi in tržna dejavnost:

primer Slovenije in tujine

\section{Oblike vodenja visokošolskih ustanov}

Skupno načrtovanje dejavnosti in njihovo pregledno vrednotenje spodbujata strukturno integracijo ustanov. Za učinkovitejše usklajevanje pa ni nujno potrebna centralizirana uprava ali vodstvo. Uprava institucije, pa tudi njeni znanstveni organi, lahko s svojo avtoriteto pospešijo visokošolsko integracijo. Tako eni kot drugi, ali pa oboji skupaj, lahko izdelajo in nato izvajajo sprejeto integracijsko politiko, ki pripomore $k$ usklajevanju visokošolskega dela (The Nature of Academic Organisation, CHEPS, 1999). Najnovejše sredstvo za pospeševanje integracije je uporaba marketinške logike. Tako se krepita vpliv in odgovornost pri načrtovanju in razporejanju sredstev podskupinam visokošolske ustanove.

\section{Oblikovanje novih visokošolskih programov}

Potrjevanje novih visokošolskih programov kot tudi notranja organizacija šol je $\vee$ večini evropskih držav $\vee$ pristojnosti resornih ministrstev. $\vee$ Sloveniji sprejema takšne odločitve Svet za visoko šolstvo na pobudo visokošolskih organizacij. Obstajali naj bi trije kriteriji, ki omogočajo sprejemanje odločitev o potrebnem preoblikovanju in novem grupiranju razdrobljenih študijskih programov, in sicer (The Nature of Academic Organisation, CHEPS, 1999, str. 90):

1. oblikovanje novih programov glede na znanstvene discipline,

2. prerazporejanje obstoječih programov in vsebin glede na cilje novih programov,

3. oblikovanje novih programov glede na potrebe trga.

\section{Mehanizmi visokošolske integracije}

Številne visokošolske ustanove v Evropi so začele uvajati nove organizacijske oblike, s katerimi želijo olajšati pretok informacij vzdolž hierarhične lestvice med vsemi posamezniki in skupinami, ki so neposredno povezane $z$ akademskim, administrativnim ali vodstvenim delom. Organizacijske strukture, ki ne zagotavljajo zadostne vzporedne in dovolj prožne komunikacije ali vsiljujejo nepotrebno hierarhično togost, so $\vee$ razmerah, kjer sta prilagodljivost in 
Mojca Potočnik Kogovšek

Visokošolski zavodi in tržna dejavnost:

primer Slovenije in tujine

akademska inovativnost nujno potrebni, obsojene na propad. Kajti vse večja zapletenost nalog in dinamičnost sodobne družbe zahtevata hitro in učinkovito sprejemanje odločitev na vseh, tudi najnižjih nivojih. Rešitev je vpeljati položaj menedžerjev za koordinacijsko funkcijo med skupinami v procesu integracije. $V$ svoji vlogi odgovarjajo vodstvu ustanove ter so uradno zadolženi za to, da je področje, za katero so odgovorni, primerno usklajeno in informacijsko povezano z drugimi področji. Koordinatorji so lahko prodekani za raziskovalno delo ali doin podiplomski študij.

\section{Zakonska opredelitev dejavnosti in financiranja visokošolskih zavodov v Sloveniji}

Javni zavod lahko ustanovi država, občina ali druga oseba javnega prava, praviloma za opravljanje neprofitnih družbenih dejavnosti - javne službe, lahko pa tudi za opravljanje druge nepridobitne dejavnosti, če se opravlja na način in pod pogoji, ki veljajo za javno službo. Zasebni zavod je praviloma ustanovljen za opravljanje storitev zunaj javne službe, oba pa lahko opravljata obe dejavnosti. Pri upravljanju in razpolaganju s premoženjem javnih zavodov se pojavlja težava. Ker so se sedanji javni zavodi večinoma razvili iz delovnih organizacij in je prišlo do podržavljanja premoženja, imamo $v$ teh zavodih lastnino ustanovitelja (države) in lastnino zavoda. Zato je upravičeno vprašanje, ali naj lastnino zavoda obravnavamo kot zasebno ali kot javno (po Kamnarjevi, 1998, str. 47). Z Zakonom o visokem šolstvu in Odlokom o preoblikovanju Univerze $v$ Ljubljani je Republika Slovenija ustanovila Univerzo v Ljubljani s članicami.

Zakon o visokem šolstvu (Uradni list RS, št. 100/04) v 72. členu kot vire financiranja visokošolskih zavodov navaja:

a) pridobivanje sredstev iz proračuna Republike Slovenije

b) pridobivanje sredstev iz šolnin in drugih prispevkov za študij

c) plačila za opravljene storitve

d) dotacije, dediščine in darila

e) sredstva iz drugih virov.

Sredstva iz proračuna RS so namenjena za pedagoško in z njo povezano znanstvenoraziskovalno, umetniško in strokovno dejavnost. Sem sodi tudi knjižničarska, informacijska, organizacijska, upravna in druga infrastrukturna dejavnost na visokošolskih zavodih, ki jo imenujemo študijska dejavnost. Financira 


\section{Mojca Potočnik Kogovšek \\ Visokošolski zavodi in tržna dejavnost: primer Slovenije in tujine}

se tudi univerzitetni šport in obštudijska dejavnost študentov, katere aktivnosti morajo biti določene $v$ letnem programu študentskega sveta univerze ali visokošolskega zavoda. Proračunska sredstva so namenjena še investicijam in investicijskemu vzdrževanju ter razvojnim in drugim nacionalno pomembnim nalogam, določenim $v$ pravilniku, ki ga sprejme minister, pristojen za visoko šolstvo. Sredstva za omenjene namene se izračunajo na podlagi števila vpisanih študentov in diplomantov na posameznem visokošolskem zavodu (Zakon o visokem šolstvu, Ur. list RS, št. 100/04).

Sredstva, zbrana s šolninami, so namenjena izvajanju študija od delu. Iz šolnin se financirajo tudi investicije in investicijsko vzdrževanje fakultet, saj so sredstva iz proračuna za ta namen skromna. Drugi prispevki študija so vpisnine, članarine za knjižnice, zamudnine, nadomestila za uporabo informacijske tehnologije, nakup literature in drugo. Plačila za opravljene storitve pomenijo tržno dejavnost posameznega visokošolskega zavoda oziroma fakultete. Tržna dejavnost pomeni prodajo proizvodov in storitev, ki jo fakultete opravljajo poleg opravljanja javne službe.

Zavod načeloma lahko ustvari presežek prihodkov nad odhodki - (dobiček), vendar pa ne glede na vir pridobivanja tega dobička ne sme razdeliti, ampak ga lahko porabi za opravljanje in razvoj dejavnosti, kar je značilno za neprofitne organizacije. Javni zavodi morajo kot proračunski uporabniki svoje prihodke in odhodke izkazati po načelu denarnega toka, in sicer zaradi spremljanja gibanja javnofinančnih prihodkov in odhodkov na ravni države. $V$ izkazu prihodkov in odhodkov prikažejo ločeno prihodke za izvajanje dejavnosti javne službe in prihodke od prodaje blaga in storitev na trgu. Prihodki za izvajanje javne službe se nadalje delijo na prihodke iz sredstev javnih financ in prihodke iz drugih virov za izvajanje javne službe.

Tržno dejavnost dovoljuje 48. člen Zakona o zavodih (Uradni List RS, št. 18/98) v primeru, da je namenjena opravljanju dejavnosti, za katero je bil javni zavod ustanovljen. Značilnost tržne dejavnosti je ustvarjanje dobička, obdavčljivost tako prodaje kot tudi dohodkov in izpostavljenost konkurenci. K prihodkom od prodaje blaga in storitev na trgu spadajo le tisti prihodki, ki jih javni zavod ustvari s prodajo tistega blaga in storitev, ki niso opredeljene kot javna služba. Tržna dejavnost javnih zavodov je opredeljena zelo ozko, zato je je relativno malo. Za javno službo je značilno, da gre pri njej za zadovoljevanje javnih potreb. Pri izkazovanju prihodkov velja splošno načelo, da so prihodki za izvajanje javne službe vsi prihodki, ki jih javni zavod prejme za opravljanje storitev javne službe, ne glede na to ali gre za prihodke iz javnih ali zasebnih virov. Po 
Mojca Potočnik Kogovšek

Visokošolski zavodi in tržna dejavnost:

primer Slovenije in tujine

22. členu Zakona o zavodih (Uradni list RS, št. 12/91) se kot javne službe opravljajo z zakonom oziroma odlokom občine ali mesta, na podlagi zakona določene dejavnosti, katerih trajno in nemoteno opravljanje zagotavlja $v$ javnem interesu država (v njenem imenu Vlada Republike Slovenije), občina ali mesto (ustanovitelj). Najbolj pristojna za pojasnjevanje, kaj sodi v javno službo, so resorna ministrstva, $v$ tem primeru Ministrstvo za visoko šolstvo, znanost in tehnologijo. Ministrstvo za visoko šolstvo, znanost in tehnologijo je zavzelo stališče, da sodijo prihodki od šolnin med prihodke opravljanja javne službe. Fakulteta na podlagi finančnih kalkulacij, ki jih sprejme Upravni odbor Univerze $\checkmark$ Ljubljani, določi višino šolnin za posamezno študijsko leto. Cena šolnine naj bi pokrivala neposredne stroške dela, neposredne stroške materiala in posredne stroške.

Zakon o računovodstvu (Uradni list RS, št.23/99) v 9. členu določa, da je treba zagotoviti ločeno spremljanje javne in tržne dejavnosti. Za ugotavljanje uspešnosti poslovanja posamezne dejavnosti je ključnega pomena čim doslednejše razmejevanje odhodkov in prihodkov med obema vrstama dejavnosti (16. člen Zakona o računovodstvu).

Odhodki, ki se nedvoumno nanašajo na določeno dejavnost, se lahko že na podlagi dokumentacije neposredno pripišejo ustrezni dejavnosti. Drugi odhodki se razvrščajo na podlagi meril (sodil), ki jih predpisuje 23. člen Pravilnika o sestavljanju letnih poročil za proračun, proračunske uporabnike in druge osebe javnega prava (Uradni list RS, št. 115/02). Merila naj bi pripravilo Ministrstvo za visoko šolstvo, znanost in tehnologijo, glede na to, da jih ni, pa se lahko uporabi razmerje med prihodki, doseženimi pri opravljanju posamezne dejavnosti. Ta merila obravnava tudi Slovenski računovodski standard številka 36.15 za ugotavljanje spremenljivih in stalnih stroškov posameznih javnih služb, posredno pa se to nanaša tudi na tržno dejavnost.

Dejstvo je, da javni zavodi kot neprofitne institucije $v$ delu, ki se nanaša na izvajanje javne službe, financirane iz javnih virov, konec leta prikazujejo pozitivne ničle. Tržna dejavnost pa dovoljuje prikazovanje presežka prihodkov nad odhodki in je tako enakovredna družbi z omejeno odgovornostjo, ki nastopa na trgu. Gre za dva nasprotujoča si pojma, ki javne zavode in s tem tudi gospodarske družbe postavlja v neenakovreden položaj.

Glede na to, da zaposleni na fakultetah poleg osnovne dejavnosti, ki jo financira ministrstvo, opravljajo tudi naloge, ki se nanašajo na nejavne prihodke, je Vlada RS sprejela uredbo o plačilu iz naslova le tega. 
Na podlagi Zakon o sistemu plač v javnem sektorju (ZSPJS) (22.i člen) je bila sprejeta Uredba o dodatni delovni uspešnosti iz naslova prodaje blaga in storitev na trgu (Uradni list RS, št. 69/2008), ki določa prihodke od prodaje blaga in storitev na trgu in zgornji obseg sredstev, ki se lahko uporabi za plačilo delovne uspešnosti iz naslova prodaje blaga in storitev na trgu.

\section{Visokošolski zavodi in tržna dejavnost}

$\checkmark$ Sloveniji nimamo jasno opredeljenega odnosa do tržne dejavnosti javnih zavodov. Na splošno prevladuje mnenje, da imajo javni zavodi, ki jih financira država, na trgu določeno prednost in da zato njihova tržna dejavnost pomeni nelojalno konkurenco gospodarskim podjetjem, ki pridobivajo svoj dohodek samo na prostem trgu. Še posebej kritičen je odnos do tržne dejavnosti, ki jo opravljajo visokošolske organizacije, pri tem pa uporabljajo za svojo dejavnost na trgu drago laboratorijski opremo, ki jo je financirala država, oziroma naj bi, po mnenju kritikov, pri svoji tržni dejavnosti izkoriščali poceni delovno silo študentov. Anketa, ki sem jo izvedla med fakultetami za arhitekturo $v$ tujini, ne potrjuje takšnega mnenja, saj je temeljni namen tržne dejavnosti fakultet predvsem njihovo povezovanje z gospodarstvom, in sicer zato, da se povežejo teoretična znanja s praktičnimi izkušnjami.

Zaradi pomanjkanja jasnega koncepta o odnosu med javnimi službami in gospodarstvom, prihaja $\vee$ praksi do številnih nejasnosti. Tako ugotavlja Računsko sodišče Slovenije pri revidiranju tržne dejavnosti javnih zavodov tele pomanjkljivosti (glej Suhadolnik, 2005, str.5):

a) ni enotnega pristopa k razmejevanju prihodkov javne službe od tržne dejavnosti

b) resorna ministrstva niso natančneje opredelila sodil za razporeditev odhodkov na javno službo in tržno dejavnost

c) javni zavodi nimajo izdelanih sodil za razporeditev odhodkov na obe vrsti dejavnosti, ki bi bili opredeljeni $\vee$ njihovih notranjih predpisih in bi jih dosledno upoštevali

d) ni usklajenega ugotavljanja tržne dejavnosti po zakonu o računovodstvu in ugotavljanja tržne dejavnosti zaradi določanja obsega sredstev za povečano delovno uspešnost, kar povzroča težave vsem udeleženim. 


\section{Mojca Potočnik Kogovšek \\ Visokošolski zavodi in tržna dejavnost: \\ primer Slovenije in tujine}

\section{Tržna dejavnost tujih fakultet}

Izvedla sem anketo med dvajsetimi evropskimi in neevropskimi arhitekturnimi fakultetami. Ugotavljam, da 86,6\% vseh vprašanih tujih fakultet izvaja tržno dejavnost tudi v okviru državnih univerz, kar omogoča njihova nacionalna zakonodaja. Večji delež tržne dejavnosti izvajajo pri doktorskem študiju (60\%) in podiplomskih tečajih $(86,6 \%)$ ter pri uresničevanju raziskovalnih projektov $(100 \%)$ in strokovnem delu (80\%), najmanjši delež pri dodiplomskem študiju (33,3\%). Polovica vprašanih fakultet s tržno dejavnostjo ustvari okoli 10\% dohodka, četrtina anketiranih fakultet ustvari okoli $20 \%$ prihodka iz tržne dejavnosti, 30\% ali več prihodka pa ustvari le 15\% fakultet. Kar 86,6\% fakultet izvaja tržno dejavnost z neposredno zaposlenimi na fakulteti, 40\% fakultet je $v$ ta namen organiziralo fakultetni inštitut, 26,6\% fakultet pa izvaja tržno dejavnost na drugačen način. 66,6\% vprašanih fakultet je odgovorilo, da vključujejo študente $\vee$ tržno dejavnost kot izvajanje prakse. Ustvarjeni dohodek od tržne dejavnosti se največkrat deli tako, da pripada manjši del dohodka fakulteti, drugo pa neposrednim izvajalcem, z odbitkom stroškov za administracijo (40\%). V manjšini so fakultete, kjer pripada prihodek $v$ celoti neposrednim izvajalcem, pri četrtini vprašanih fakultet pa ostaja prihodek fakulteti, z odbitkom neposrednih stroškov za izvajalce in administracijo. Dobra polovica vprašanih fakultet izvaja tržno dejavnost s sodelovanjem gospodarstva (53,3\%), hkrati pa ugodno ocenjujejo korist tržne dejavnosti za razvoj fakultete, ker omogoča hiter prenos univerzitetnega znanja $\vee$ prakso $(73,3 \%)$, omogoča prenos znanj iz prakse na univerzo $(80 \%)$ in prispeva pomemben delež sredstev za razvoj fakultete $(66,6 \%)$.

$\checkmark$ večini držav, kjer opravljajo tržno dejavnost, so študentje le posredno vključeni v ta proces, kot opazovalci ali v neprofitnem delu tržne dejavnosti, kjer se pridobljena sredstva namenijo za njihove študijske potrebe. Sodelujejo pri študentskih delavnicah ali terenskih oziroma laboratorijskih raziskavah $\vee$ praksi, ki jih izvajajo v okviru obveznih vaj pri predmetih. Na vprašanje, ali izvajajo tržno dejavnost organizirano s sodelovanjem gospodarstva, je polovica fakultet odgovorila pritrdilno, polovica pa z gospodarstvom sodeluje občasno in na podlagi javnih razpisov.

Vsi anketiranci so bili mnenja, da je tržna dejavnost fakultet koristna in profesorjem ter študentom omogoča stik s prakso, hkrati pa prinaša pomemben delež prihodka fakultet, ki je namenjen nadaljnjemu razvoju. 


\section{Javna služba in tržna dejavnost Fakultete za arhitekturo}

Fakulteta za arhitekturo (FA) je imela do leta 1998 registracijo za opravljanje projektantskih dejavnosti (sodni register Okrožnega sodišča v Ljubljani z datumom 14.10.1996). Po mnenju Inženirske zbornice Slovenije je to pomenilo nelojalno konkurenco na enotnem trgu ponudbe projektantskih storitev. $\vee$ zbornici so bili prepričani, da ima fakulteta pri svoji tržni dejavnosti manjše režijske stroške ter da lahko uporablja pri svojem delu cenejšo študentsko delovno silo. Zato je bilo fakulteti pooblastilo odvzeto. $V$ takšnih razmerah so se pedagoški delavci FA odločili, da ustanovijo družbo z omejeno odgovornostjo. $\vee$ njenem okviru še naprej izvajajo svojo strokovno in umetniško dejavnost, pri čemer dela praviloma potekajo na podlagi tripartitnih pogodb med naročnikom, izvajalcem in FA. Na ta način ostajajo reference in del finančnih sredstev tudi v okviru fakultete.

\section{Dvojna vloga fakultetne administracije}

Fakultete so zainteresirane za tržno dejavnost vsaj iz dveh razlogov:

a) $S$ tržno dejavnostjo pridobivajo fakultete in njihovi delavci potrebne strokovne in raziskovalne reference, na podlagi katerih lahko uspešneje konkurirajo na vse bolj zaostrenem evropskem trgu znanja.

b) $S$ tržno dejavnostjo lahko pridobijo fakultete tudi del svežih sredstev za lasten razvoj, denimo za nakup opreme, za investicije, obštudijske dejavnosti študentov in podobno.

Največjo korist in tudi motiv za tržno delo imajo pedagogi in raziskovalci ter fakulteta kot institucija. Hkrati je delo na trgu dodatno breme za fakultetno administracijo. Večina fakultet pavšalno zaračunava delež od pogodbenega zneska, ki je namenjen delu administracije. Ta delež je pogosto fiksen, ne glede na količino dodatno opravljenega dela, in zato ne pomeni stimulacije za delo administracije. To je še posebej očitno pri evropskih raziskovalnih projektih, pri katerih fakulteta praviloma ne zaračunava režijskih stroškov, zaradi česar je administracija prisiljena opravljati svoje delo volontersko. 
Mojca Potočnik Kogovšek

Visokošolski zavodi in tržna dejavnost:

primer Slovenije in tujine

\section{Predlogi rešitev na primeru Fakultete za arhitekturo}

Danes postopoma izginjajo razlike med različnimi oblikami visokošolskih organizacij in hkrati se povečuje njihov interes za povezovanje z gospodarstvom. Razvoj teži k tako imenovani učeči družbi, kjer so $v$ proces izobraževanja in raziskovanja vpletene vse ravni družbenega in gospodarskega življenja $\vee$ najrazličnejših medsebojnih povezavah, kar bo $v$ prihodnje omogočilo optimalno izkoriščanje vseh intelektualnih oziroma človeških virov ter sinergijo njihovega medsebojnega delovanja. Tudi $\vee$ Sloveniji se bodo univerze po pričakovanju $v$ prihodnje tesneje povezale $z$ gospodarskimi organizacijami in si tako zagotovile del sredstev za svoj razvoj tudi na trgu (Jasna Kontler Salomon, Delo, 2006). S tem v zvezi predlagamo na FA vrsto novosti in sicer:

a) Vpeljati je treba funkcijo prokurista oziroma prodekana za finančno področje.

b) Fakulteta mora opredeliti jasne cilje in namene delovanja na trgu.

c) Z razvojnim menedžmentom mora fakulteta nuditi oporo neposrednim izvajalcem dela na trgu.

d) Raziskovalcem, ki prevzemajo evropske projekte, je treba nuditi ustrezno administrativno logistično podporo ter zagotoviti sredstva za plačilo stroškov med posameznimi fazami izvedbe projektov.

e) Fakulteta naj si prizadeva za organizacijo mednarodnega podiplomskega študija z dolgoročnimi akademskimi in politično-ekonomskimi učinki, ko gre za uveljavljanje slovenskega znanja in podjetništva na tujih trgih (Program dela Fakultete za arhitekturo, 2006/2009). Študentje iz tujine bodo postali ambasadorji slovenskih interesov na tujem.

f) Fakulteta se mora učinkovito povezati z novim Univerzitetnim podjetniškim inkubatorjem in z Inovacijsko-razvojnim inštitutom Univerze, ki je v ustanavljanju.

g) Ohraniti je treba obliko organiziranja profesorjev kot družbenikov $v$ družbi z omejeno odgovornostjo (UNIARH d. o. o.), v okviru katere izvajajo profesorji na trgu projektantsko-umetniško delo, ki je pogoj za njihovo akademsko napredovanje.

h) Z gospodarskimi organizacijami naj fakulteta organizira skupne razvojne inkubatorje, $v$ katerih bi sodelovali tako pedagogi in raziskovalci kot 


\section{Mojca Potočnik Kogovšek \\ Visokošolski zavodi in tržna dejavnost: primer Slovenije in tujine}

študentje ali strokovnjaki iz prakse in v okviru katerih bi študentje s finančno pomočjo zainteresiranih naročnikov uresničili raznovrstne vzorčne projekte.

i) Fakulteta naj organizira karierni center, v okviru katerega bo ciljno, za trg in usmerjeno došolala diplomante na željo in na račun zainteresiranih bodočih uporabnikov.

j) Na FA je treba razviti mrežni sistem vodenja, ki naj hkrati vključuje hierarhično in tržno obliko notranje organiziranosti fakultete.

k) Z novo organiziranostjo fakultete, ki pomeni kombinacijo hierarhičnega in nehierarhičnega vodenja in finančnega poslovanja, bo jasneje opredeljeno razmerje pedagogov in raziskovalcev do fakultetne administracije, saj bodo administrativne posle $\vee$ okviru tržne dejavnosti po dogovoru in za ustrezno plačilo opravljalo fakultetno osebje, ki bi imelo $\checkmark$ tržni dejavnosti dopolnilno zaposlitev in možnost strokovnega napredovanja.

I) S predlaganim načinom organizacije tržne dejavnosti, ki bi jo pretežno izvajali v okviru posameznih projektnih skupin, razvojnih inkubatorjev in omenjene družbe $z$ omejeno odgovornostjo, se bo sistem evidenc ločil na tiste, ki so $v$ pristojnosti države in fakultete kot izvajalke javne službe na račun javnih sredstev in na tiste, ki pripadajo dejavnosti, kjer nastopa fakulteta na trgu (tudi za del javne službe, ki je ne financira država).

\section{Zaključek}

Navedla sem številne argumente, ki govorijo v prid uvajanju tržne dejavnosti na visokošolskih zavodih in opisala predlog potrebnih in možnih organizacijskih preureditev, ki izvirajo iz potrebe po večji dinamičnosti in tržni konkurenčnosti visokošolskih zavodov. S tem sem dokazala povezavo med kakovostno organizirano tržno dejavnostjo na visokošolskih zavodih in možnostjo njihovega vsestranskega razvoja ter krepitve njihove konkurenčnosti, predvsem pa pozitivne učinke povezovanja fakultet $s$ prakso pri krepitvi vezi med akademskim in strokovnim okoljem, kar bo predvsem v prid študentom. Hkrati se potrjuje hipoteza, da je tržna dejavnost neizogibno potrebna, če želijo pedagogi ohraniti in razvijati stik z živo stroko, kar kažejo težnje pri razvoju evropskega visokega šolstva. To sem potrdila $z$ anketo na tujih fakultetah in $z$ analizo 
Mojca Potočnik Kogovšek

Visokošolski zavodi in tržna dejavnost:

primer Slovenije in tujine

sodobnih gibanj $\vee$ razvoju evropskega visokega šolstva. Predlagam izvajanje tržne dejavnosti $\vee$ treh večjih sklopih: pri raziskovalnem in ekspertnem delu v povezavi z gospodarstvom, pri podiplomskem in izrednem študiju, ki poteka $v$ okviru fakultete brez proračunskih sredstev, ter pri projektantski dejavnosti. Na podlagi rezultatov, ki sem jih pridobila $\vee$ okviru svoje raziskave, predlagam novo organiziranost fakultet, ki temelji na kombinaciji hierarhičnega in nehierarhičnega vodenja in finančnega poslovanja fakultet. Menim, da je za realizacijo ideje o policentričnosti oziroma razpršenosti univerzitetne strukture treba razvijati zahtevnejše oblike notranje organizacije, ki bodo kombinacija tradicionalne hierarhične oblike vodenja (od zgoraj navzdol) in mrežnega, nehierarhičnega nivojskega in mednivojskega povezovanja, utemeljenega na diskrecijski pravici strokovnih vodij manjših, tržno in projektno usmerjenih akademskih skupin, ki delujejo $v$ imenu fakultet, vendar na lasten račun. $\vee$ takšnih organizacijskih razmerah bo mogoče jasno opredeliti odnose med udeleženci, se pravi med fakultetami in gospodarstvom, med fakultetami in nosilci posameznih projektov ter med posameznimi projektnimi skupinami in fakultetno administracijo. Predlagam projektno organiziranost tržne dejavnosti na fakultetah, ki bo omogočila razvoj novega znanja; to se bo $v$ okviru mrežne organiziranosti prenašalo tudi v akademsko sfero in jo plemenitilo z novimi izkušnjami. S svežim kapitalom bo mogoče pridobiti nove pedagoške in raziskovalne kadre ter kupiti potrebno opremo, kar bo nedvomno pozitivno vplivalo tudi na obseg ponudbe in na kvaliteto učnega programa, namenjenega študentom. Vsekakor menim, da je treba pravočasno opozoriti visokošolske organizacije na napovedane sistemske spremembe, da se lahko nanje pripravijo z oblikovanjem razvojnih strategij, ki bodo upoštevale tudi potrebo po povečanem deležu tržne dejavnosti in po aktivnejšem odnosu do gospodarstva.

Mojca Potočnik Kogovšek je leta 2001 na Fakulteti za upravo zagovarjala diplomsko nalogo z naslovom "Program Tempus v Sloveniji - problemi, rezultati in priporočila". Leta 2007 je na isti fakulteti zaključila specialistični študij z nalogo s področja tržne usmerjenosti fakultet. Zaposlena je na Fakulteti za arhitekturo kot pomočnica tajnika za finančne zadeve. 


\section{Mojca Potočnik Kogovšek \\ Visokošolski zavodi in tržna dejavnost: primer Slovenije in tujine}

\section{Literatura}

- Clark, Burton R.(1995). Complexity and Differentiation: The Deepening Problem of University Integration. In: D.D. Dill \& B. Sporn (Eds). Emerging Patterns of Social Demand and University Reform: Through a Glass Darkly, Oxford: Pergamon Press, str.159-169.

- Goedegebuure, L. et al. (Eds.). (1993). Higher Education Policy, An International Comparative Perspective. Oxford: Pergamon Press.

- Kamnar, H. (1998): „Konflikt med avtoriteto ustanovitelja in avtonomijo javnega zavoda«, magistrsko delo. Univerza v Ljubljani, Fakulteta za družbene vede.

- Kogan, M.(1992). New trends in higher education research in Europe and their relationship to key issues in European highcr education and higher education policy: Three issues on the research agenda'. In: Frackmann E. \& Maassen P. (Eds.). Towards Excellence in European Higher Education in the '90s, Utrecht, Lemma, str. 63-68.

- Kontler-Salamon, J. Slovo klasičnih univerz: pogovor z novim predsednikom Podonavske rektorske konference, Delo, 25.9.2006.

- Neave, G. (2000). The universities responsibilitiies to society. International perspective. Amsterdam: IAU, Elsevir.

- $\quad$ Odlok o preoblikovanju Univerze v Ljubljani. Uradni list RS, št. 28/00, 33/03, 79/04, 36/06.

- Pravilnik o sestavljanju letnih poročil za proračun, proračunske uporabnike in druge osebe javnega prava. Uradni list RS št. 115/02, 21/03, 134/03, 126/04.

- Program dela Fakultete za arhitekturo. 2006-2009.

- Suhadolnik, V. (2005). Upravljanje in evidentiranje tržne dejavnosti v javnih zavodih, Konferenca Računskega sodišča, Ljubljana.

- Uredba o dodatni delovni uspešnosti v javnem sektorju. Uradni list RS, št. 14/2006, 136/2006, 69/2008.

- Zakon o računovodstvu. Uradni list RS, št. 23/99, 30/02.

- Zakon o sistemu plač v javnem sektorju. Uradni list RS, št. 56/02, 72/03, 126/03, 70/04, 53/05, 14/06, 27/06, 68/06, 1/07, 57/07.

- Zakon o visokem šolstvu. Uradni list RS, št. 67/93, 39/95, 18/98, 35/98, 99/99, 64/01, 100/03, 134/03, 63/04, 100/04, 94/06.

- Zakon o zavodih. Uradni list RS, št. 12I/91,45I/94, 8/96, 18/98. 
Mojca Potočnik Kogovšek

Visokošolski zavodi in tržna dejavnost:

primer Slovenije in tujine

SUMMARY

\section{HIGHER EDUCATION INSTITUTIONS AND MARKET ACTIVITIES: A CASE STUDY OF SLOVENIA}

The market activity of higher education institutions is important for their general development, which is why optimal conditions need to be created for its performance to the advantage of all faculty members, the profession and students. The basis for changes in financing higher education in Europe is the Erfurt Declaration "Towards the Responsible University of the Twenty-first Century", adopted in March 1999. It contains a directive stating that universities should find additional financial resources, whereby they achieve greater financial autonomy, but also assume greater responsibility. This results in the diversification, privatisation and businessisation of higher education. One of the fundamental purposes of the new market-oriented government policies is the introduction of more pronounced competitiveness between all higher education institutions. This is why states strive for more volatility and instability in the field of public financial assistance. Competitive environments should prompt institutions to reform their internal organisational structures in order to achieve better performance and, at the same time, produce innovative academic, research and accompanying programmes of interest as much to the students as to potential sponsors willing to finance research projects in the field of the private sector. With respect to the foregoing, some questions and problems are being posed in Slovenia:

a) Should market activity inside Slovene higher education institutions be supported?

b) Should market activity be carried out on behalf of faculties or universities?

c) What should be the ratio between public and market activities in higher education institutions?

In the paper, answers to the above questions are presented, and the link between the quality of organisation of market activity in higher education institutes and their possibilites for all-round development is shown. 
As the matter is vaguely defined legally, the purpose of the research was to find deeper theoretical and practical reasons for maintaining and developing market activities in public institutes - faculties in Slovenia.

In connection with the issue under discussion, three starting hypotheses were formulated as follows:

a) market orientation in higher education is important for stimulating greater competition among all types of higher education institutions.

b) restructuring the internal organisation of higher education institutions is necessary for the adaptation of public institutes to new social and economic conditions in the knowledge market.

c) linking higher education with the economy is important for the professional, scholarly, pedagogical and economic development of higher education institutes.

Today, most European countries tend toward the development of new organisational models in higher education, which would be founded on traditional forms, but would simultaneously introduce new methods required by a contemporarily organised society. They seek parallels in the organisational models of contemporary business organisations, which are organised in a more dynamic fashion than traditional higher education models. Different to business organisations, activities of higher education institutions (research, preserving and spreading knowledge) are prevailingly non-profit. Universities have aims that are much more long-term than might be expected in business organisations. The market dictates the need for new, specialised higher education programmes which contribute to the forming of fresh pedagogical and research units within the framework of higher education institutions. Differentiation is a necessity, but higher education specialisation contributes to accelerated organisational fragmentation, as investigations in new areas require fresh teaching staff, new departments and new research centres. Therefore, new forms of management of higher education institutions and integration process are a significant part of organisational efforts, and impose great liability upon the administration of higher education institutions. Vertical communication constitutes one of the possibilities for linking structures, whereby different work groups are hierarchically linked, and subordinated and ac- 
Mojca Potočnik Kogovšek

Visokošolski zavodi in tržna dejavnost:

primer Slovenije in tujine

countable to a common leader. But there are also horizontal mechanisms for linking structures, which prompt regular mutual communication between individuals and groups, thus enhancing the processing of the data of the entire organisation.

This is of importance in forming new higher education programmes which are being evolved with regard to scholarly disciplines, the objectives of the new programmes or market demands. In most European countries the forming of new higher education programmes is in the province of line ministries. In Slovenia, such decisions are taken by the Council for Higher Education on the initiative of higher education organisations. Fresh programmes bring greater differentiation, therefore new forms of management and integration of higher education institutions need to be established. Because of the necessary balance between differentiation and integration, a compromise will probably be needed between new approaches and traditional forms which once helped organise the academic work. The development of an appropriate academic structure is therefore the prime objective of the academic and administrative management. Moreover, it is important to achieve a legal definition of the activity and the financing of higher education institutes in Slovenia, which is still vague, especially in regard to market activities at the faculties. In Slovenia, a public institute may be founded by the State, a municipality or other public entity, usually for non-profit social activities - i.e. public services. But it may also be founded for other non-profit activities if they are carried out according to the terms and conditions in force for public services. A private institute is established for carrying out services outside the public service, but either may perform both activities. As to the management and disposal of the assets of public institutes, there is a problem. As actual public institutes have predominantly developed from working organisations in the process of nationalisation, we have to deal in these institutes with the assets of the founder (i.e. the State) and the institute's assets. Consequently, a justified question emerges: should the institute's assets be regarded as private or public property? Market activity at faculties is allowed by Art. 48 of the Institutes Act (Official Gazette of RS, $\left.n^{\circ} 18 / 98\right)$, providing it is intended for carrying out the activity that the institute had been founded for. The characteristics of market activity are the creation of profit, taxability of sales and income, and exposure to competition. 
In Slovenia there is a critical, even negative attitude to market activities performed by higher education organisations which in the process use expensive laboratory equipment financed by public funds and - in the opinion of critics - exploit cheap student labour. A survey carried out among faculties of architecture abroad does not corroborate this opinion, since the basic purpose of market activities of foreign faculties is primarily liaising with the economy in order to link theoretical knowledge to practical experiences. The author found that $86.6 \%$ of all faculties surveyed carry out market activities within the framework of public universities, which is allowed by their national legislation. However, students are not included in the profitable activities of the faculties. The survey investigated the forms of introduction of market activity at Ljubljana's Faculty of Architecture and found that through market activity the faculty acquires the necessary professional and research references, as well as some financial resources for development, used for example for purchasing equipment, investments, extra-curricular activities of the students and similar. Here the important dual role of the school's administration should be mentioned: it bears an additional burden through the introduction of marketing, and needs to be suitably financially motivated. The survey suggests a range of new solutions which may facilitate and stimulate the evolution of market activity. Among others, it suggests carrying out market activities in three large complexes of labour and services supply: teachers' and investigators' research and expert work in connection with the business sector; graduate and part-time study which takes place at the faculty without public funding; and professional activities performed by individual teachers either within the framework of faculty institutes or their own limited liability companies.

On the basis of the analysis of the existing situation, a new organisation of faculties has been proposed. It is based on a combination of hierarchical and non-hierarchical management and financial operation. To this end, it will be necessary to evolve more demanding forms of internal organisation. They will be a combination of traditional hierarchical topdown management, and networked, non-hierarchical intra-level and interlevel 'wiring' resting on the discretionary rights of professional leaders of small, market and project oriented academic groups acting on behalf of faculties, but on their own account. In such organisational conditions it will be possible to clearly define the relations between the participants i.e. between faculties and the business sector, between faculties and holders of individual projects, and between individual project groups and faculty 
Mojca Potočnik Kogovšek

Visokošolski zavodi in tržna dejavnost:

primer Slovenije in tujine

administration. The proposed project organisation of the market activity will enable the growth of fresh knowledge. Networked organisations will transfer this knowledge into the academic sphere, too, enriching it with new experience. Fresh capital will make it possible to attract new teaching and research staff and purchase the necessary equipment, which will positively influence the scope and quality of the study programmes for students. 